\section{HOW TO MAKE LIVING VIRAL TATTOOS}

Tagny Duff ${ }^{1}$ with Jill Muhling ${ }^{2}$, Maria Grade Godinho ${ }^{2}$, Stuart Hodgetts ${ }^{2}$.

( ${ }^{1}$ Intermedia, Communication Studies, Concordia University and SymbioticA, The Centre For Excellence in Biological Arts situated in the ${ }^{2}$ School of Anatomy and Human Biology at The University of Western Australia) E-mail:

$<$ tduff@alcor.concordia.ca>.

Submitted: 27 July 2009

\section{Abstract}

Living Viral Tattoos (2008) is a research-creation project featuring the development of sculptures made in vitro. The creation of tattoos in the form of made in vitro. The creation of tattoos in the form of
blue 'bruises' on pig skin and donated human skin was made using retroviruses, cell and tissue culture and immunohistochemical stains. This technical paper presents the protocols created and materials used in the project with the intention of contributing to an open source model for the development of to an open source model for the development of
wetware and biological art processes. Keywords: wetware and biological art processes. Keywords:
biological art, viral media, tissue culture, collaboration, open source, interdisciplinary.

Today, synthetic retroviruses, such as Lentivirus, are regularly used in laboratories to transport genes and markers to various 'target' areas, and immuno stains are used to visualize viral and cellular reactions. Living Viral Tattoos is a research-creation project featuring the same process of immunohistochemical staining to visualize infected cells on the surface of human and pig skin and render a blue 'bruise' that is perceptible to the human eye. Conceptually, the idea of using the movement of virus to create the 'bruise' is the focus of artistic expression rather than delivering a gene of interest for scrutiny. The rendering of the 'bruise' is not scientific or medical. No contusion has occurred on the skin. Rather, the stain rendered in the form of a bruise is a reference to current tensions and social anxiety regarding biotechnology and the viral. My intention in using Lentivirus as an artistic medium and subject is to explore how perceptions and tensions around infection and contagion might be re-imagined and rearticulated by engaging with viral vectors [1]

This project and technical paper are a collaboration between myself, Stuart Hodgetts, Maria Grade Godinho and Jill Muhling. Given the interdisciplinary nature of the project, where techniques and technical terminology from the life sciences may be less familiar to the arts and humanities, just as artistic processes are less familiar to the sciences, an open source ethic and sharing of technical development are necessary. This article outlines how scientific techniques, such as tissue culture engineering, the transduction of viral vectors and immunohistochemical staining on skin, are used for the creation of sculptures.

The language and format used in this text is a hybrid of an artist project statement and science paper. The scientific terminology used to describe the artistic process challenges the expectations of

Fig. 1. Living Viral Tattoos (2008) A research-creation project and series of sculptures. Tagny Duff in collaboration with Ionat Zurr, Maria Grade Godinho, Jill Muhling, Oron Catts and Stuart Hodgetts. Materials: Human and pig skin, HaCat Cells, Myoblasts, Lentivirus, Red Fluorescent Protein, immunohistochemical stains. (C) Tagny Duff)

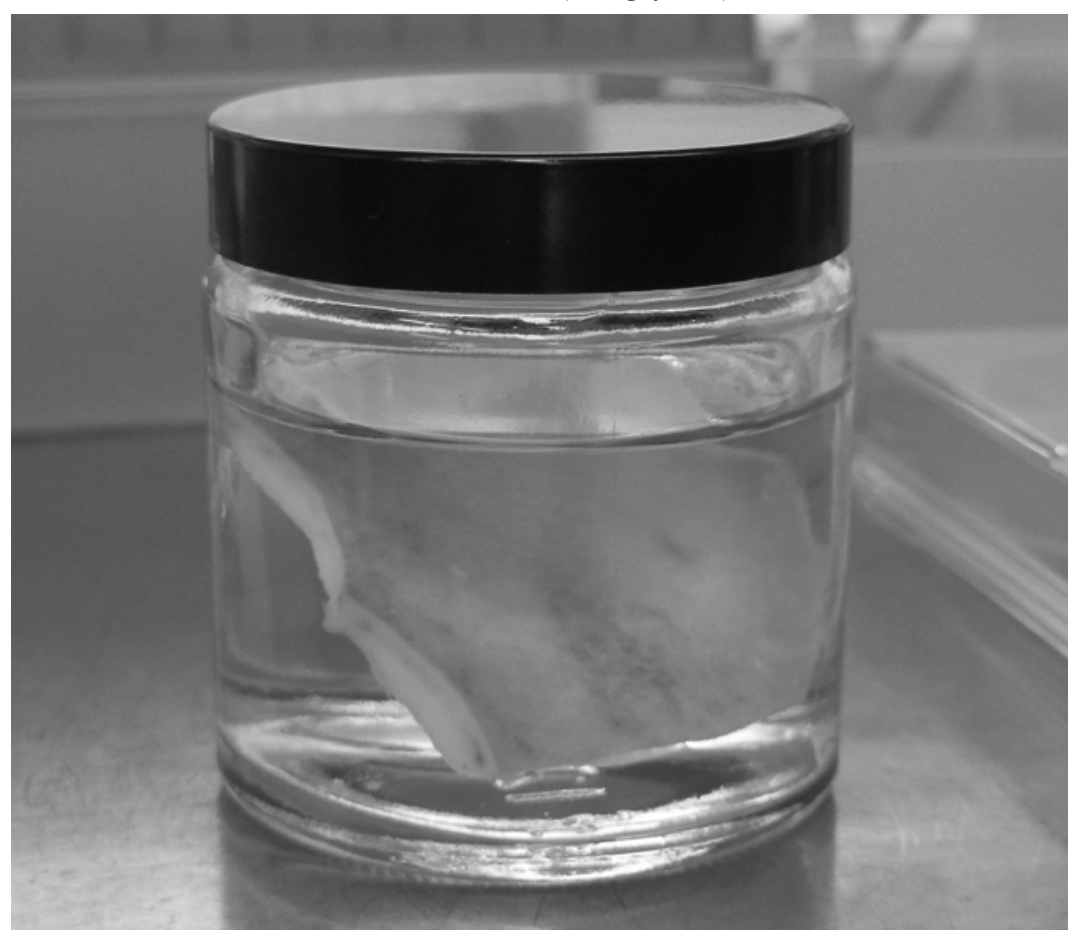

linguistic expression and material application, just as my use of the first person and the basic premise of the science technique described here may not meet the standards of a science journal [2]. In doing so, this text intentionally explores the convergence of our various knowledge sets as artists and scientists collaboratively applied towards the making of Living Viral Tattoos (2008) [3].

\section{Preparing Pig and Human Tissue for Transfection}

The first series of sculptures depicting the 'bruise' on the surface of skin was created on pigskin bought from a local butcher. After ethics and biosafety approval was received from Concordia University and The University of Western Australia, I met with a plastic surgeon and made arrangements to seek the donation of skin from a consenting patient undergoing elective surgery for breast reduction. The skin was collected from the hospital immediately after the surgery was completed and delivered to the lab. Both human and pig skins were cut into smaller pieces, placed in fourwell petri dishes and washed with phosphate buffered saline (PBS) in preparation for transfection with the Lentiviral vector.

\section{Lentiviral Transduction}

The transfection of the skin consisted of many steps that occurred over a 10 month period of planning, organizing and application. Early on in the process I purchased two frozen vials of custom made infectious, non-replicative Lentivirus (BioGenova) and had these mail ordered from a biotech company in the USA. The Lentivirus was genetically modified to express red fluorescent protein (RFP) and titred at $1 \times 10^{7}$ transducing particles $/ \mathrm{mL}$. Both vials were thawed, and each of the 200 microliters $(\mu \mathrm{l})$ of viral supernatant aliquoted at $1 \times 10^{4}$ into microcentrifuge tubes before freezing in storage at $-80^{\circ} \mathrm{C}$. I worked in the lab at SymbioticA where I grew human endothelial HaCat cells and murine primary myoblasts from skeletal muscle with the direction of Ionat Zurr and Stuart Hodgetts and additional help by Guy Ben-Ary. Once the Lentivirus arrived and all elements for the transfection process were organized, I plated the cells in 24-well dishes overnight with DMEM nutrient solution and $10 \%(\mathrm{v} / \mathrm{v})$ Fetal Bovine Serum. When the cells were $60 \%$ confluent, the Lentivirus was thawed and $10 \mu 1$ was added to each cell type to test the multiplicity of infection (MOI). The next day, medium was removed and 
replaced with fresh medium, then incubated again for twelve hours. The cells were washed in PBS, and trypsinized in $0.25 \%(\mathrm{w} / \mathrm{v})$ trypsin/10mM EDTA.

(Trypsin is an enzyme for lifting the cells from the plates and suspending them, so that the cells may be passaged). At that point, I resuspended the viral host cells in more media and then transplanted them onto the skin substrate.

\section{Fixing and Staining Sculptures}

While all of us had direct input into technical production of this project, it was Stuart Hodgetts who modified the immunohistochemical staining protocol to render the areas where the lentiviraltransduced cells had transfected the 'host' skin [4]. In this process, cells are fixed so that enzyme reactions can be observed in the form of colour coding (using a chromagen).

A number of steps were taken to fix and stain the sculptures. First, the suspended viral host cells were pipetted and transplanted directly onto sections of skin tissue and incubated for 4 hours. In order to render the bruise, a fixative was first added to the tissue to produce cell death and (in theory) neutralize the viral movement. Proteins and secondary structures (including nucleic acids ie. RNA, DNA) found in the tissue were crosslinked by the fixative and antigens "revealed" for binding to antibodies. The tissue was fixed with 1:1 (v/v) acetone: methanol for 5 minutes then incubated with primary antibodies (used to locate the antigen of interest) for $30 \mathrm{~min}$. at $37^{\circ} \mathrm{C}$. The tissue was then rinsed three times with PBS to remove unbound antibody and incubated with secondary antibodies (ImmunoPure Goat Anti-Rabbit Peroxidase Conjugated and ImmunoPure Peroxidase Conjugated Goat AntiMouse, which are specific for the primary antibodies) for $30 \mathrm{~min}$. at the same temperature. A rinse with L-15 was performed three times, with another series of PBS washes. After antigen:antibody reactivity a chromagen solution was applied to the tissue. The blue staining that co-localises with the applied virus was achieved using 4-chloro-1-naphthol $(4 \mathrm{CN})$ chromagen solution. The colour blue was produced wherever the transfected cells proliferated in or on the dermal layers of skin. The extent of blue colour depicting a 'bruise' was enhanced to the desired intensity by submerging the tissue in tap water for 2 days to intensify the 4CN staining.

After the staining process was completed, one piece of transfect and trans-
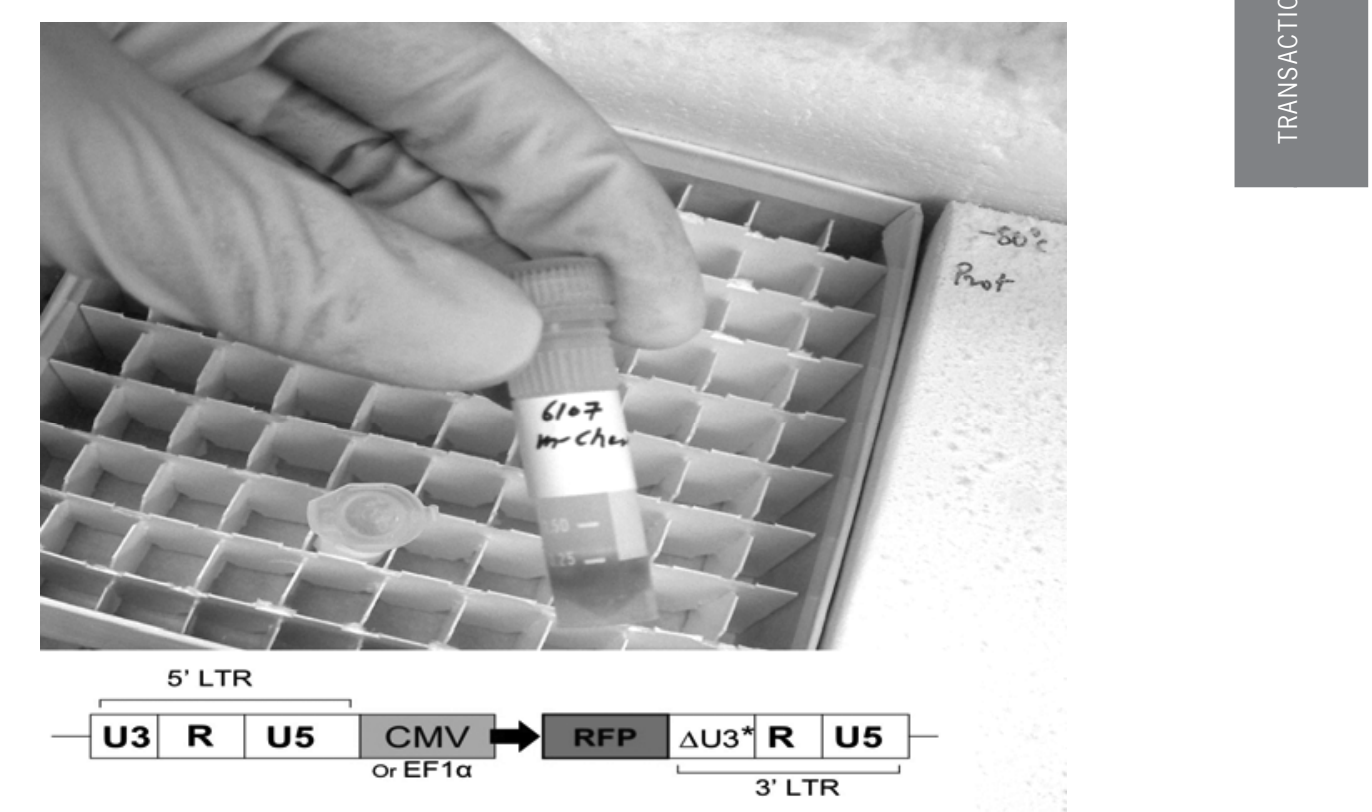

Fig. 2. Image and diagram of frozen Lentivirus with Red Fluorescent Protein. (C) Tagny Duff)

genic human and pig skin, respectively, were put into a small glass jar filled with paraformaldehyde. A total of 8 skin sections are displayed in 4 specimen jars. The sculptures have since been relocated in new glass containers containing PBS and are currently displayed at Symbioti$\mathrm{cA}$ and the School for Anatomy and Human Biology at the University of Western Australia.

\section{Conclusion}

The overview of the technical development of Living Viral Tattoos is intended for open source sharing and distribution. Biological art processes and wetware are emerging in new artistic practices and interdisciplinary research. This text intends to contribute to an expanded understanding of some key methods, tech nologies and terminology used towards these ends. It may also be seen as a tactic for scoring the document so that it may be repeated and remixed by other interested practitioners and researchers. [5]

Our collaborative work reflects recent negotiations that are occurring between artists and scientists. At points, this text lends itself to technical scientific language. If the artistic use and theoretical and conceptual discourses around wet ware and biotechnology are to evolve in the arts and humanities, it is necessary to grasp both the scientific processes and the terminology. Other sections are vague and personalized. Researchers in the applied life sciences are implicated in the development of art and biotechnology by having to learn 'art speak'. The cross pollination creates a hybridity that does not settle comfortably in one discipline or the other. However, borrowing terminology from the life sciences, the "hybrid vigour' may well be advantageous for both fields of research.

\section{References and Notes}

1. A longer exploration of the artistic, conceptual and philosophical implications of this project is forthcoming in the PhD dissertation by Tagny Duff entitled Moist Media Documents: Viral contagion from performance to documentation.

2. "People in the humanities, for their part, tend to take a piecemeal approach to application. They will isolate an attractive scientific or mathematical concept and add it to the repertoire of their own disciplinary system, like an exotic pet. Scientists might rightly object that the concept has ceased to have anything remotely scientific about it and is jus functioning as a metaphor." Massumi, Brian. Pafunctioning as a metaphor." Massumi, Brian. Pa-
rables for the Virtual. Movement, Affect and Sensation. (Durham; Duke Univ. Press. 2002) p. 19. Scientists, on the other hand, are aware of the need to borrow from methodology and practice in the humanities to expand the accessibility to scientific research and publication. See 'How to Write Consistently Boring Scientific Literature' by Kaj SandJsen: < www.indiana.edu/ halllab/GradRes/ Boring Writing.pdf $>$.

3. The research-creation project, part of a $\mathrm{PhD}$ dissertation undertaken by Tagny Duff at Concordia University, was produced with the collaborative efforts of Tagny Duff, Ionat Zurr, Jill Muhling, Maria Grade Godinho and Stuart Hodgetts. The PhD reserch is suprvist The the lab work by Ionat Zurr. This research was done at SymbioticA, The Centre For Excellence in Biological Arts in the School of Anatomy and Human Biology at the University of Western Australia between 2007 and 2008. The research was funded by The Social Sciences and Humanities Research Council of Canada and the Fonds de recherche sur Council of Canada and the Fonds de recherche sur
la société et la culture. Human ethics and biosafety approval for this research was obtained through UWA and Concordia University.

4.This protocol was developed by Stuart Hodgetts. The full protocol and its ongoing developing can be found at: $<\underline{\text { http://cryobookarchives.wordpress.com }>\text {. }}$

5. For more thoughts on this read MacDonald, Corina. Scoring the Work: Documenting Practice and Performance in Variable Media Art. Leonardo. 42, No. 1, (February 2009) pp. 59-63. 